\title{
Seepage Characteristics of Slurry with Particle Additives in the High-Permeability Sand Layer
}

\author{
Yuan Wang $\mathbb{D}^{1,2,3}$ Zhikui Wang, ${ }^{1}$ Di Feng, ${ }^{1}$ Sijin Liu, ${ }^{4}$ Shujun $X u,{ }^{4}$ and Kun $\mathrm{Zhou}^{4}$ \\ ${ }^{1}$ College of Civil and Transportation Engineering, Hohai University, Nanjing 210098, China \\ ${ }^{2}$ College of Water Conservancy and Hydropower Engineering, Hohai University, Nanjing 210098, China \\ ${ }^{3}$ State Key Laboratory of Hydrology-Water Resources and Hydraulic Engineering, Hohai University, Nanjing 210098, China \\ ${ }^{4}$ China Railway 14TH Bureau Group Co., Nanjing 210098, China
}

Correspondence should be addressed to Yuan Wang; wyhhu1995@163.com

Received 12 January 2021; Revised 2 March 2021; Accepted 18 March 2021; Published 9 April 2021

Academic Editor: Bin Gong

Copyright (c) 2021 Yuan Wang et al. This is an open access article distributed under the Creative Commons Attribution License, which permits unrestricted use, distribution, and reproduction in any medium, provided the original work is properly cited.

In the process of the slurry shield construction, the formation of the filter cake is the key to maintain the stability of the excavation face. In high-permeability formation, ordinary pure bentonite slurry is easy to pass through the formation void. Therefore, it is necessary to study the slurry permeability characteristics of the high-permeability sand layer. For the purpose of researching the permeability characteristics of slurry in sandy formation, this paper studies the influence of slurry viscosity on the formation of the filter cake in high-permeability formation under different pressure gradients by the slurry permeability test. The effect of additive particle size on the film-forming gain was studied by adding additives with different particle sizes into pure bentonite slurries with different viscosities. This paper presents a method to determine the optimum slurry viscosity and particle size for high-permeability formation so as to guide the slurry shield construction in high-permeability formation.

\section{Introduction}

The slurry shield tunnel has been widely used in recent years, especially in the urban subway and river crossing tunnel. However, during the slurry shield construction in the highpermeability stratum, the pure bentonite slurry inrush caused disasters frequently, which seriously affect the stability of the shield construction face. In order to maintain the stability of the slurry shield excavation face during construction, it is necessary to prevent the slurry suspension from penetrating into the soil. To ensure the effective transmission of support pressure to the soil, it is necessary to form a dense low-permeability filter cake on the face of the tunnel [1-7]. For highly permeable soils, pure bentonite suspensions cannot be used anymore, which penetrate the ground, and the required suspension pressure may not be attached. It is necessary to add chemical additives (tackifier, dispersant, etc.) [8] and coarse-grained materials (vermiculite, sand, clay, quartz powder, sawdust, fiber, etc.) [8-14] to improve the slurry properties. When the slurry permeates the formation, it could reduce the formation permeability and form the membrane more quickly and efficiently.

For the purpose of researching the effect of slurry particle additives on formation permeability, Fritz [8] considered the influence of additive polymer, sand, and vermiculite on the maximum slurry pressure and determined the composition proportion of the best combination. The slurry pressure that the best combination could bear is more than 10 times higher than that of using ordinary bentonite slurry. Han et al. [9] and Liu et al. [15] compared the effective gap of the formation with the minimum particle size and the maximum particle size of the slurry and divided the formation state of the membrane into three types: filter cake type, permeability zone type, and filter cake and permeability zone type. Liu et al. $[15,16]$ took light sand as coarse-grained material. By comparing the relationship between the particle size of coarse-grained material and the pore diameter of formation, it was found that the addition of coarse-grained material is more conducive to the formation of the filter cake, and the coarse-grained material with a smaller particle size could 
produce a good synergistic effect with slurry particles. Min et al. $[11,12]$ defined the average pore diameter soil through the formation permeability coefficient and pore ratio, compared the average pore diameter with the particle size of representative slurry particles, and divided the seepage phenomenon into three categories.

For the purpose of researching the influence of slurry viscosity on formation permeability, Min et al. [12] showed that increasing the content of clay particles was more conducive to the formation of the filter cake, but only the content of clay particles (clay particles less than $0.005 \mathrm{~mm}$ ) in the slurry could be used as an important index for slurry adjustment. The effect of coarse particles in the slurry was ignored. Wang et al. [17] and Min et al. [18] regarded the slurry as Bingham fluid, tested the slurry performance with a rotary viscometer, and established the relationship between the yield stress which can characterize the viscosity of the slurry and the initial pressure gradient in the process of mud infiltration. The yield stress is positively correlated with the initial pressure gradient. Zhai et al. [19] and $\mathrm{Xu}$ and Bezuijen [14] regarded slurry infiltration as a kind of formation silting process and increased slurry viscosity by increasing bentonite content. It is concluded that increasing the viscosity of slurry is more conducive to the formation of the filter cake. In the process of slurry shield circulation, the slurry plays an important role in carrying slag, so the slurry should have good fluidity. Therefore, previous studies were mostly limited to lowviscosity mud (marsh time 30 40s). However, in the highpermeability stratum, the shield machine is in the rest state and does not need to carry slag. At this time, the primary role of slurry is not to carry slag but to form the filter cake. In other words, grouting must be used in the highpermeability stratum to reduce the permeability in front of the excavation face. The use of high-viscosity bentonite slurry has become the first choice [20].

Therefore, it is necessary to carry out the influence of slurry viscosity and particle size on the formation of the filter cake in high-permeability formation. The relationship between the slurry viscosity and the pressure gradient of pure bentonite was established by the slurry permeability experiment. The influence of slurry viscosity on the formation of the filter cake in high-permeability formation under different pressure gradients is studied. By adding additives with different particle sizes to pure bentonite slurry with different viscosities, the effect of additive particle size on the gain effect of filter cake formation was studied. In this paper, a method of optimum slurry viscosity and particle size suitable for the high-permeability stratum is proposed to guide slurry shield construction in the high-permeability stratum.

\section{Experimental Studies}

2.1. Materials. Two kinds of materials were used to simulate the formation of the filter cake, which were pure bentonite slurry material formed by bentonite and water and slurry material added with coarse additives. The pure bentonite was composed of different clay particles; it was mixed material. However, its clay particle size was less than $0.075 \mathrm{~mm}$,
TABLE 1: Basic physical indexes of the test soils.

\begin{tabular}{lccc}
\hline Identity of soil & $\mathrm{S} 1$ & $\mathrm{~S} 2$ & $\mathrm{~S} 3$ \\
\hline Grain size range $(\mathrm{mm})$ & $2-3$ & $3-4$ & $4-5$ \\
Dry density $\left(\mathrm{g} / \mathrm{cm}^{3}\right)$ & 1.45 & 1.49 & 1.53 \\
$n$ & 0.43 & 0.40 & 0.36 \\
$K(\mathrm{~m} / \mathrm{s})$ & $1.86 \times 10^{-2}$ & $3.87 \times 10^{-2}$ & $4.97 \times 10^{-2}$ \\
$\overline{D^{\prime}}(\mu \mathrm{m})[11]$ & 305 & 456 & 544 \\
\hline
\end{tabular}

which was 1-2 orders of magnitude smaller than that in additives, so it was defined as pure bentonite slurry $[8,21]$.

To investigate the influence of slurry viscosity and particle size of additives on the formation of the high-permeability sand film, four pure bentonite slurry materials [11, 19] were prepared, respectively. After screening, impurities were removed from the bentonite, and bentonite particles with particle sizes less than or equal to $0.075 \mathrm{~mm}$ [12] were obtained. Five kinds of coarse-grained additive materials with different particle sizes were prepared $[8,16]$. For the integrity and accuracy of the experimental data, three kinds of coarse sand with different particle sizes $[11,16]$ were also prepared as high-permeability formation materials for slurry permeability. Slurry materials and formation materials would be described in detail below.

2.1.1. Stratum Materials. For the integrity and accuracy of the experimental data, three kinds of high-permeability formations with different permeability coefficients and pore ratios were constructed in the paper. The construction method was to obtain three kinds of uniform sand with particle sizes of $2-3 \mathrm{~cm}, 3-4 \mathrm{~cm}$, and $4-5 \mathrm{~cm}$ through four kinds of standard sieves with diameters of $1 \mathrm{~mm}, 2 \mathrm{~mm}, 3 \mathrm{~mm}$, and $4 \mathrm{~mm}$, named S1, S2, and S3, respectively. The basic physical indexes of the experimental formation materials were measured by the standard of the soil conventional parameter test, as shown in Table 1.

The permeability of soil is affected by its porosity and pore size distribution. It is difficult to accurately measure the pore size of sand, so some conceptual models and empirical equations are used to estimate the pore size of the formation. The average pore size of a formation is equivalent to the pore size of a formation [11, 22-24]. The accuracy of the formula $\left(\overline{D^{\prime}}=\sqrt{K /(31 \times 1.5 n)}\right)$ is verified by the experimental comparison between the calculated data of formation average pore size in Min et al.'s paper and the data of the PoreMaster60GT mercury injection instrument. Therefore, this paper selects the formula as the standard for calculating the average pore size $\overline{D^{\prime}} .\left(\overline{D^{\prime}}\right.$ is the average pore diameter size of soil.)

2.1.2. Slurry Materials. According to the different research emphases, two kinds of slurry materials were prepared. To investigate the influence of the relationship between the viscosity of pure bentonite slurry and the pressure gradient of slurry, the first kind of slurry was prepared as pure bentonite slurry (i.e., the content of particle additives was zero). The pure bentonite slurry was a mixture of sodium bentonite 
TABLE 2: Mass of each constituent in slurry.

\begin{tabular}{lccc}
\hline Type of slurry & The content of bentonite (\%) & The particle diameter of additives & Marsh time (s) \\
\hline SL1 & 7.4 & No contain & $22 \mathrm{~s}$ \\
SL2 & 13.7 & No contain & $68 \mathrm{~s}$ \\
SL3 & 19.4 & 0 and $0.2 \mathrm{~mm} \sim 0.6 \mathrm{~mm}$, namely, SL3 and SL31 SL35, respectively & $155 \mathrm{~s}$ \\
SL4 & 24.2 & No contain & 210 \\
\hline
\end{tabular}

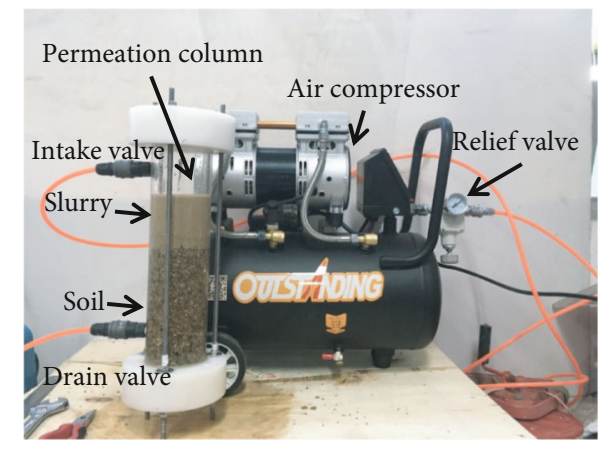

FIgURE 1: Filter cake airtightness test apparatus.

and CMC $(0.04 \%$, a high molecular polymer $[11,25])$ and water. In order to reflect the effect of slurry viscosity on formation silting better, we choose the method of increasing bentonite content in this paper. Four kinds of pure Na-bentonite slurries with concentrations of $7.4 \%, 13.7 \%, 19.4 \%$, and $24.2 \%$ were prepared, which were named SL1-SL4, respectively.

To investigate the influence of the silting effect of particle size additives on formation, the average pore sizes of S1, S2, and S3 were $0.305 \mathrm{~mm}, 0.456 \mathrm{~mm}$, and $0.544 \mathrm{~mm}$, respectively. In this paper, fine sand with a particle size of $0.2 \mathrm{~mm} \sim 0.6 \mathrm{~mm}$ (increment $0.1 \mathrm{~mm}$ ) and SL3 pure bentonite slurry $[15,16]$, which were widely used in high-permeability formation engineering, were selected as the second slurry in this paper, named SL32-SL36, respectively. Table 2 shows the slurry material parameters. The fine sand is selected as an additive in this paper.

2.2. Experimental Apparatus and Test Method. In this paper, the self-developed filter cake airtightness test device was used as the test device (as shown in Figure 1). The device consists of the main body of the permeation column, a pressure relief valve maintaining stable air pressure, and an air compressor providing air pressure. The inner diameter of the plexiglass cylinder is $75 \mathrm{~mm}, 10 \mathrm{~mm}$ thin, and $40 \mathrm{~mm}$ high. It could withstand a maximum pressure of about $1 \mathrm{MPa}$. An air compressor was used to provide osmotic pressure. The initial slurry pressure is $50 \mathrm{kPa}$, with $50 \mathrm{kPa}$ as an order of magnitude, and it is continuously increased to the maximum $300 \mathrm{kPa}$. In order to control and measure the pressure in the column, a pressure relief valve is used to stabilize the air pressure with a stability accuracy of $1 \mathrm{kPa}$. The main body of the permeation column is composed of the plexiglass cylinder. The air compressor could pressurize the experimental slurry in the column through the intake valve on the column. After the slurry penetrates through the formation, the rate loss of the slurry could be measured by connecting the measuring cylinder with the drainage outlet.

Before adding $5 \mathrm{~cm}$ of the cushion layer, the test was carried out at the bottom of the layer. In order to make the formation distribute evenly, the formation material was added three times. Add about $7 \mathrm{~mm}$ each time, and then hammer 10 times each time to keep the void ratio stable. Secondly, tap water was used to saturate the formation materials. Then, $500 \mathrm{~mL}$ of slurry was introduced into the top of the formation to form a slurry layer in the upper part of the formation. Finally, an air compressor was used to apply different air pressures on the upper part of the mud layer to simulate the slurry infiltration. The downward seepage that flowed through the test soil layer was recorded by using the slurry pressure method. When the pressure was applied each time, the flow rate was stable; record the corresponding slurry pressure and discharge volume. At the same time, the formation of the filter cake was observed. When the cake was formed, the test pressure ends.

\section{Results and Analysis}

3.1. Filter Cake Formation of Pure Na-Bentonite Slurry. In order to obtain the permeability law of slurry with different viscosities in high-permeability formation, the permeability of four kinds of pure bentonite slurry in three kinds of formation was analyzed by experiment device 1 . The test pressure is in the order of $50 \mathrm{kPa}$, which was continuously increased to the maximum $250 \mathrm{kPa}$. By recording the leakage under different pressures, the formation of the filter cake in the three formations was observed (it should be noted that the leakage amount here represents the water after the free water in the slurry was not fully combined with the slurry particles and penetrates through the formation under the action of consolidation) $[9,11]$. The test pressure gradient and permeability curve were established here, as shown in Figure 2. In the figure, the abscissa was the pressure action time, the left ordinate is the pressure gradient, and the right ordinate was the leakage amount.

It could be seen from Figure 2 that the filter cake of SL3 and SL4 formed in S1 and S2 formations. SL1 and SL2 did not form the filter cake. It showed that with the increase of slurry viscosity, the formation of the filter cake was easier. When the filter cake was formed, the filtering water was less, which indicated that the quality of the filter cake is better. In S3 formation, the filter cake was formed in SL4 and not in SL1-3. Although SL4 formed the filter cake, the quality was 


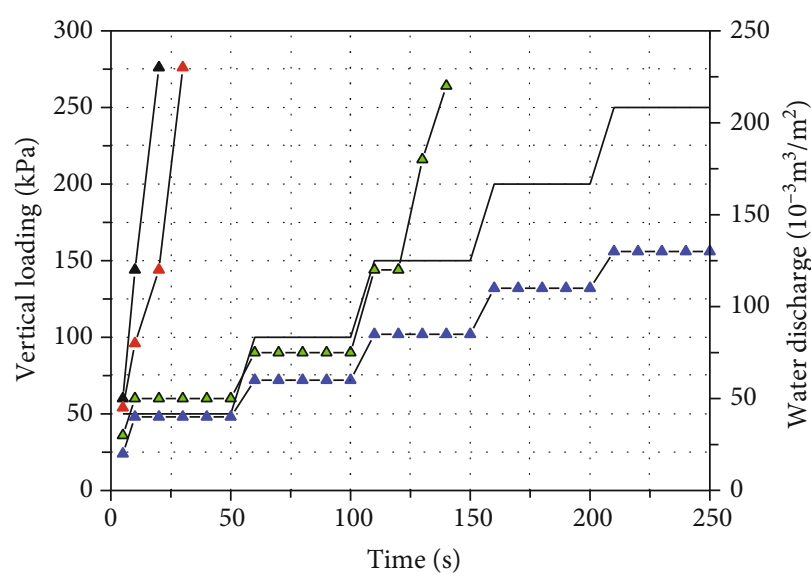

(a) $\left.\mathrm{S} 1 \overline{\left(\mathrm{D}^{\prime}\right.}=305 \mu \mathrm{m}\right)$

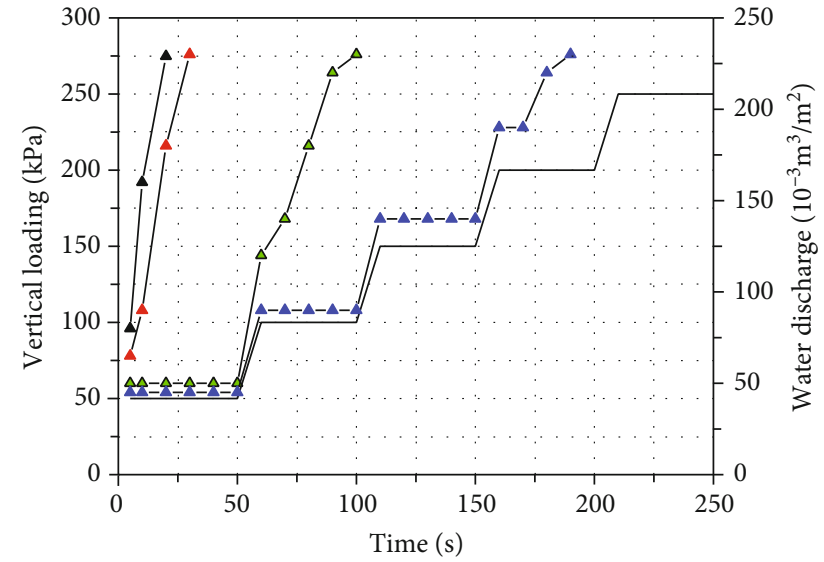

(b) $\mathrm{S} 2\left(\overline{\mathrm{D} 2^{\prime}}=456 \mu \mathrm{m}\right)$

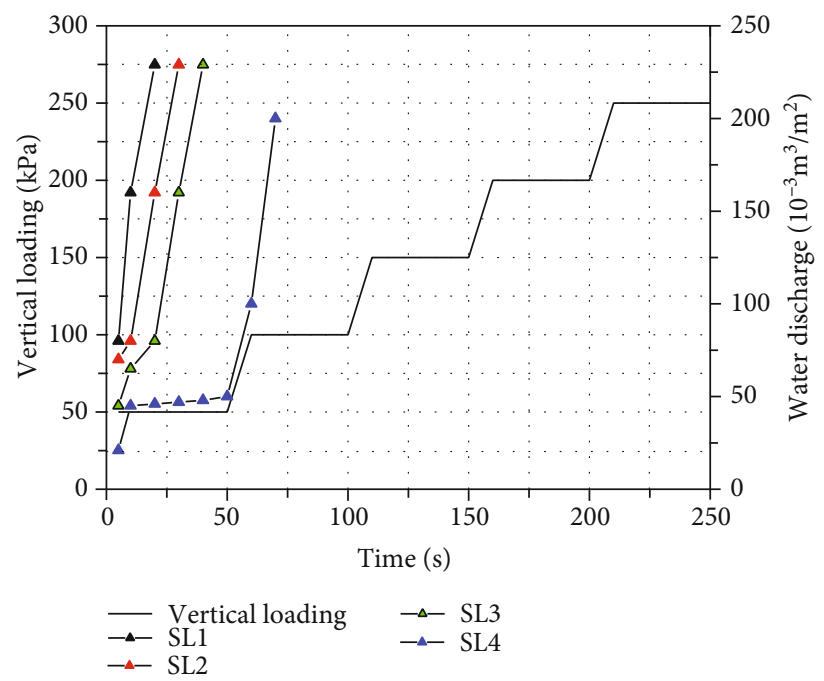

(c) $\mathrm{S} 3\left(\overline{\mathrm{D} 3^{\prime}}=544 \mu \mathrm{m}\right)$

FIgURE 2: Pressure gradient and infiltration curve of the test.

poor. When the slurry pressurized to $100 \mathrm{kPa}$, the filter cake was broken down, and the filtration volume increased rapidly. Only increasing the content of bentonite has a limited effect on the quality of the filter cake.

3.2. Filter Cake Formation of Na-Bentonite Slurry with Coarse-Grained Materials. To investigate the influence of slurry viscosity and particle size of additives on the formation of the filter cake in high-permeability formation, five kinds of bentonite slurries SL31 SL35 containing coarse-grained materials were selected to analyze their permeability in three formations. The effect of pure bentonite slurry and particle additives on the formation of the high-permeability formation filter cake was studied under different pressures. The specific experimental operation was consistent with the test operation in Section 3.2. The typical curve of the relationship between the filtration rate and the film-forming time is shown in Figure 3. In the figure, the abscissa is the pressure action time, the left ordinate is the pressure gradient, and the right ordinate is the leakage amount.
It could be seen from Figure 3 that the initial pressure of slurry leakage was increasing after adding coarse-grained materials to SL3 pure bentonite slurry. The increase of coarse particles in the slurry had a significant effect on the increase of initial mud pressure, which made it easier to form the filter cake than pure bentonite slurry.

In general, for S1 formation, the leakage tended to be stable under various pressures, and there was no trend of rapid increase. It was proved that the filter cake could be formed by adding coarse particles in the formation. Since S1 formation could form the filter cake under various pressures, S2 formation and S3 formation were mainly analyzed. For S2 formation, when the vertical pressure was greater than $150 \mathrm{kPa}$, the leakage of SL31 slurry would increase rapidly. It was proved that the filter cake could not be formed at this time. When the pressure of SL32 and SL35 slurries was higher than $200 \mathrm{kPa}$, the leakage of SL32 and SL35 slurries increased rapidly, and the filter cake could not be formed. SL33 and SL34 slurries could not form the filter cake when the pressure was greater than $250 \mathrm{kPa}$. For S3 formation, when the slurry 


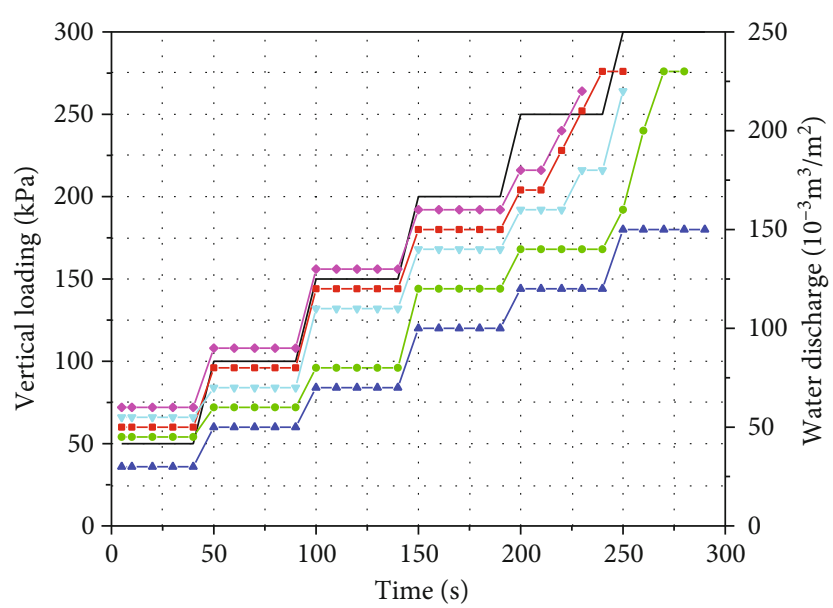

(a) $\left.\mathrm{S} 1 \overline{\left(\mathrm{D}^{\prime}\right.}=305 \mu \mathrm{m}\right)$

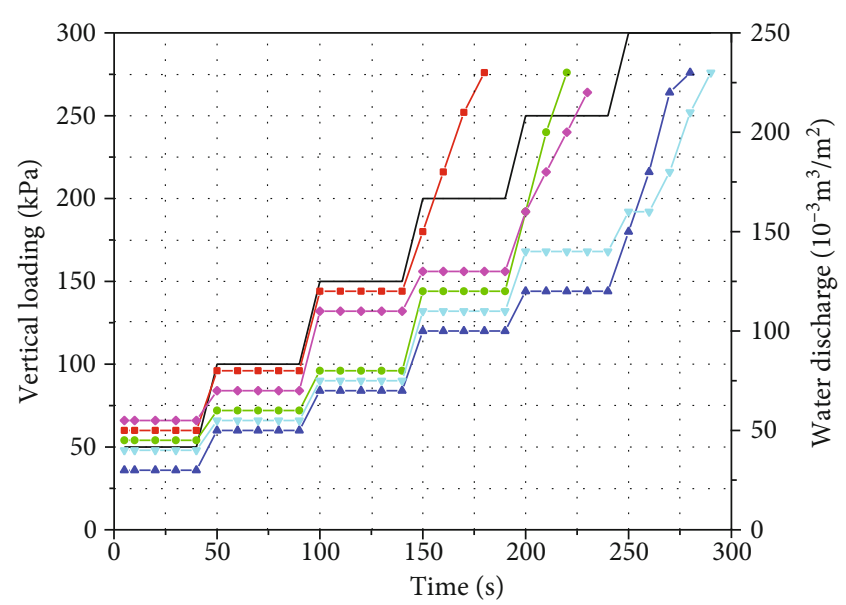

(b) $\mathrm{S} 2\left(\overline{\mathrm{D}^{\prime}}=456 \mu \mathrm{m}\right)$

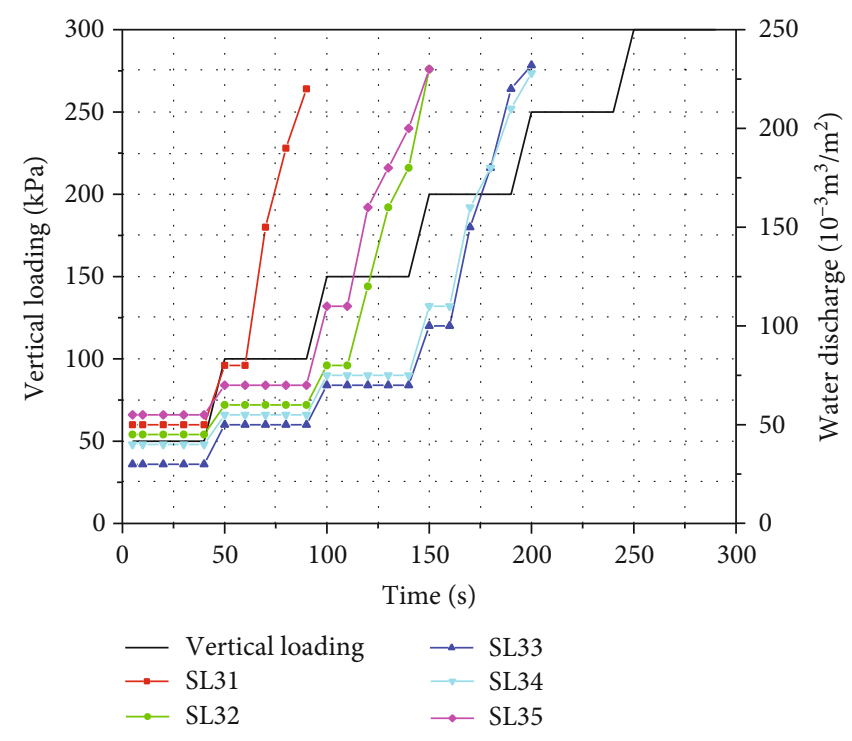

(c) $\mathrm{S} 3\left(\overline{\mathrm{D} 3^{\prime}}=544 \mu \mathrm{m}\right)$

FIgURE 3: Pressure gradient and infiltration curve of the test.

pressure was greater than $100 \mathrm{kPa}$, the leakage of SL31 slurry increased rapidly. When the vertical pressure of SL32 and SL35 slurries was greater than $150 \mathrm{kPa}$, the leakage of SL32 and SL35 slurries would increase rapidly, and the filter cake could not be formed. When the initial pressure gradient of SL33 and SL34 was greater than $200 \mathrm{kPa}$, filter cake could not be formed.

\section{Discussion}

4.1. Effect of Coarse-Grained Additives on Filter Cake Formation. Figure 4 shows the maximum pressure that five different slurry materials could bear when forming the filter cake in S2 formation and S3 formation, respectively. It could be seen from Figure 4 that with the increase of the average pore size of the formation, the maximum pressure that the same slurry could bear to form the filter cake becomes smaller. Moreover, the increase of coarse particles in the slurry had a significant effect on the increase of initial slurry pressure. The smaller size of the coarse-grained materials could reduce the filtration rate and shorten the film-forming time. However, with the increase of the particle size of coarse-grained materials, the gain effect was gradually weakened. The results showed that the gain effect of coarse-grained material on the filter cake was limited. The results showed that both the filtration loss and the formation time of the filter cake decreased at first and then increased with the increase of particle size in additives, which was similar to Gaussian distribution, as shown in Figure 4.

In Figure 3, SL32 and SL35 and SL33 and SL34 intersect in S2 and S3 formations, indicating that SL33 was more stable than SL34 and that SL32 was more stable than SL35 before the intersection. The reason may be that fine sand particles with too large particle size could not form a good synergistic effect with slurry. In addition, the fine sand with the same 


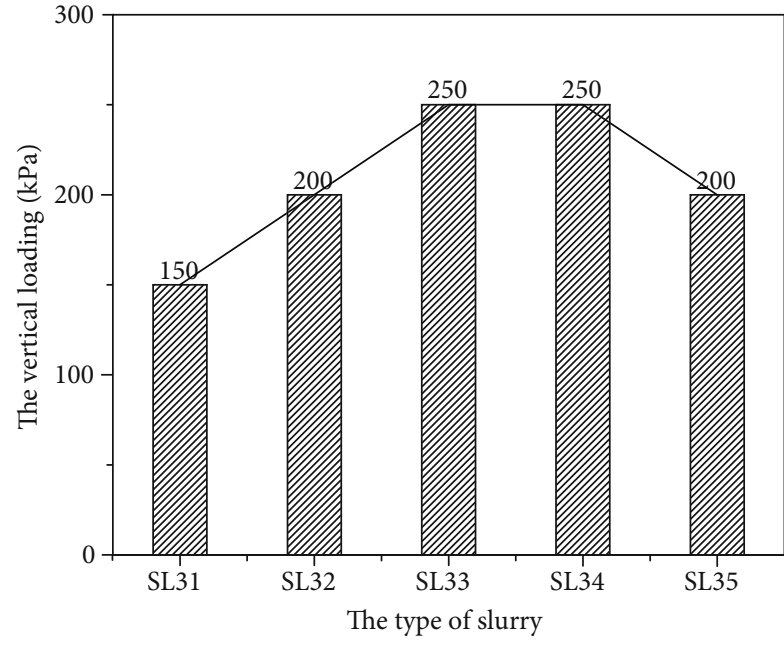

(a) $\mathrm{S} 2\left(\overline{\mathrm{D} 2^{\prime}}=456 \mu \mathrm{m}\right)$

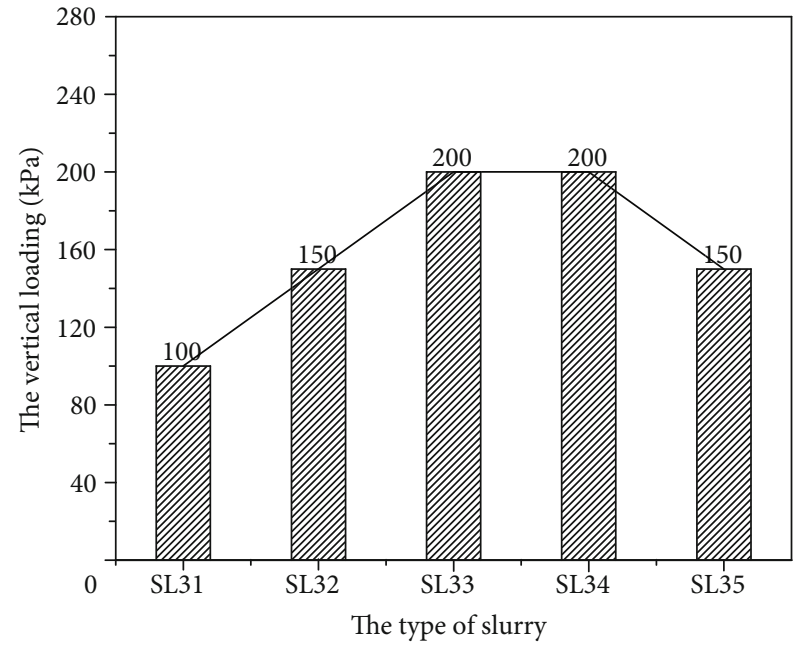

(b) $\mathrm{S} 3\left(\overline{\mathrm{D} 3^{\prime}}=544 \mu \mathrm{m}\right)$

FIGURE 4: Distribution of the maximum vertical pressure during mud film formation.

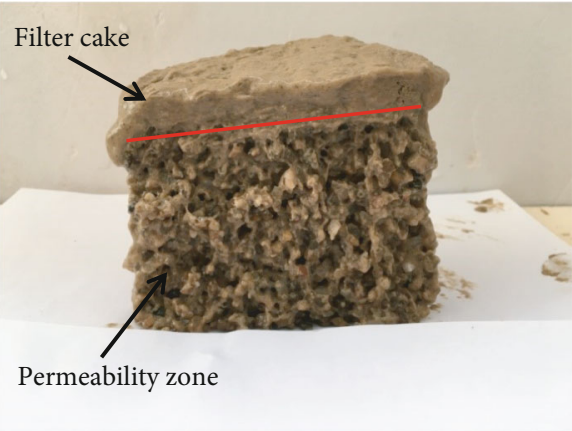

(a) Pure bentonite

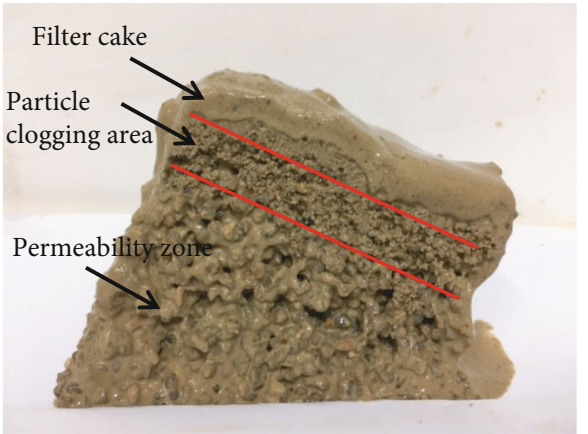

(b) Bentonite slurry with coarse-grained materials

FIGURE 5: The permeability effect of slurry in S3 formation.

content had a larger particle size and fewer particles, which led to the formation of an uneven thin filter cake and easyto-cause local damage. The selection of the particle size of coarse-grained materials was the most important factor affecting the film-forming effect. The experimental results were consistent with the experimental results of Liu et al. (2015) and also verified the reliability of the experimental results.

\subsection{Mechanism Analysis of Coarse-Grained Additives and} Slurry Viscosity on Filter Cake Formation. This section evaluated the film-forming effect of pure bentonite slurry and granular slurry. Figure 5(a) shows the final result of SL3 pure bentonite slurry forming the filter cake in S3 formation. It could be seen from the figure that the change of stratum properties could be divided into two parts: the upper part is the filter cake, and the lower part is the permeable zone. Because the clay particle size of pure bentonite slurry was less than $0.075 \mathrm{~mm}$, far less than the average pore diameter of S3 formation of $0.544 \mathrm{~mm}$, a part of clay particles penetrated into the sand layer under the action of seepage force, and most of the clay particles formed the polymer chain structure under the action of polymer CMC and formed the filter cake on the surface of the formation, as shown in Figure 5(a).

The interaction mechanism between polymer chains and clay particles is shown in Figure 6(a). In addition to bentonite, the polymer was also mixed into the slurry. The polymer with long strings forms a "net" over the pores causing a rapid clogging almost without respect to any filter law. Figure 6(a) tries to visualize this special situation. The soil-bentonite slurry would penetrate relatively deep into the pores if there were no polymer strings in the slurry mixture. The pure bentonite slurry must overcome the shear force caused by soil action before it could penetrate into the pores of the formation. When the viscosity of the slurry is high, the shear force is larger. The slurry that does not penetrate into the formation will accumulate at the excavation face, which is another way to form a filter cake.

Figure 5(b) shows the final effect of SL33 slurry (with a particle size of $0.4 \mathrm{~mm}$ ) forming the filter cake in S3 


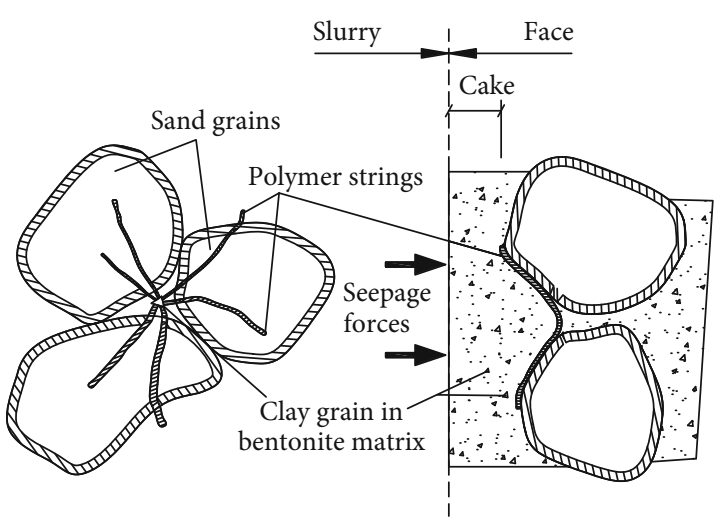

(a) Pure bentonite

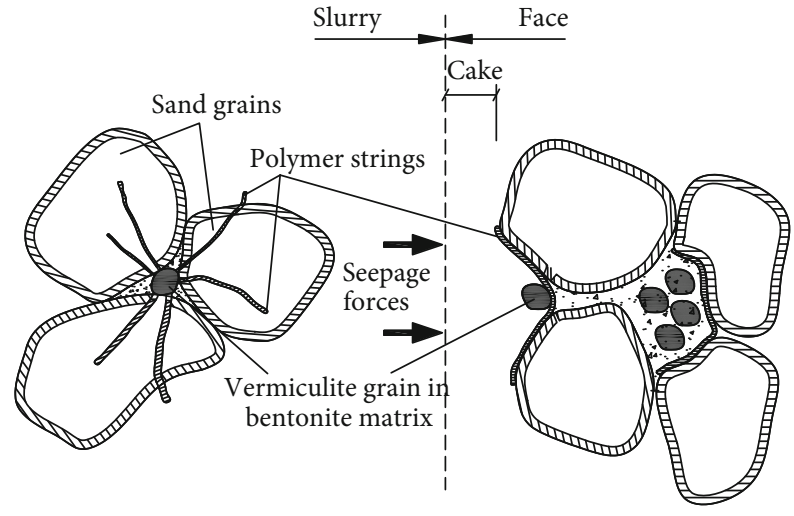

(b) Bentonite slurry with coarse-grained materials

Figure 6: Filter cake formation mechanism analysis.

formation. It could be seen from the figure that the permeability state of slurry in the formation was obviously divided into three parts: the upper part is the filter cake, the middle part is the particle clogging area, and the bottom part is the permeability zone. Due to the blocking effect of the formation voids, fine sand particles added in the slurry would be silted up after being penetrated a certain distance in front of the excavation face. It could be seen from Figure 3 that under the same level of pressure load, the filtration capacity of SL33 was about half less than that of SL3. SL33 could bear more mud pressure. Finally, the infiltration area and filter cake formation area were dried, sieved, and weighed. The $0.3 \mathrm{~mm}$ particle additive accounted for $95 \%$ of the original addition. Considering the loss of additive particles in the experiment, most of the particles were blocked in the infiltration area and filter cake. It could be seen from this that the coarse-grained materials will first be silted up in the formation pores, reducing the average pore size of the original formation and forming new pores with a smaller average pore size. The clay particles in the subsequent bentonite slurry were more likely to be silted in the average pore space of the new formation. Thus, the formed sludge membrane has lower filtration capacity and stronger antipermeability damage ability. The interaction mechanism of the polymer chain, clay, and coarse-grained materials after adding coarsegrained materials is shown in Figure 6(b) [25].

\section{Conclusion}

In view of the problem of how to form a low-permeability filter cake in high-permeability strata, this paper investigates the influence of slurry viscosity and particle size on the formation of the filter cake through the slurry permeability experiment. Some new understandings and conclusions are obtained:

(1) In high-permeability formation, increasing the content of bentonite and increasing the viscosity of slurry are reliable methods to form the filter cake quickly and maintain the support pressure of the excavation face. The formation of the polymer chain between clay particles and CMC in bentonite slurry is the reason for the rapid film formation of pure bentonite slurry

(2) Adding coarse-grained materials to slurry could effectively improve the film-forming effect. A good synergistic effect can be achieved by adding granular materials slightly lower than the average pore size of the formation and pure bentonite mud. The amount of leakage is small, and the slurry is denser. It also provides a new idea for the selection of particle size distribution in slurry. The filter cake with better quality can be formed by adding coarse particles slightly smaller than the average pore size of the formation. But the premise is to select the correct way to calculate the average pore size of the formation

(3) There are two kinds of filter cake formed by bentonite slurry in high-permeability formation: one is the filter cake with the permeable zone, and the other is the filter cake with the permeable zone and particle clogging area. The latter kind of filter cake could be formed by adding coarse additives suitable for the average pore size of the formation

(4) There are many reasons that affect the viscosity of slurry. The paper only considers the influence of bentonite content on the viscosity of slurry. The follow-up research could supplement the effect of other additives such as CMC content and a new type of HengDunNi material on the film-forming effect

\section{Data Availability}

All the data were given in this paper.

\section{Conflicts of Interest}

The authors declare that they have no conflicts of interest. 


\section{Acknowledgments}

The authors would like to acknowledge the financial support of the National Natural Science Foundation of China (Grant Nos. U1765204 and 41772340), the Graduate Research and Innovation Projects of Jiangsu Province of China (Grant No. KYCX20_0444), and the Fundamental Research Funds for the Central Universities (No. B200203089).

\section{References}

[1] G. Anagnostou and K. Kovari, "The face stability of slurryshield-driven tunnels," Tunnelling and Underground Space Technology, vol. 9, no. 2, pp. 165-174, 1994.

[2] E. H. Davis, M. J. Gunn, R. J. Mair, and H. N. Seneviratine, "The stability of shallow tunnels and underground openings in cohesive material," Geotechnique, vol. 30, no. 4, pp. 397$416,1980$.

[3] S. H. Kim and F. Tonon, "Face stability and required support pressure for TBM driven tunnels with ideal face membrane drained case," Tunnelling and Underground Space Technology, vol. 25, no. 5, pp. 526-542, 2010.

[4] G. Mollon, D. Dias, and A.-H. Soubra, "Probabilistic analysis and design of circular tunnels against face stability," International Journal of Geomechanics, vol. 9, no. 6, pp. 237-249, 2009.

[5] G. Mollon, D. Dias, and A.-H. Soubra, "Face stability analysis of circular tunnels driven by a pressurized shield," Journal of Geotechnical and Geoenvironmental Engineering, vol. 136, no. 1, pp. 215-229, 2010.

[6] G. Mollon, D. Dias, and A.-H. Soubra, "Rotational failure mechanisms for the face stability analysis of tunnels driven by a pressurized shield," International Journal for Numerical and Analytical Methods in Geomechanics, vol. 35, no. 12, pp. 1363-1388, 2011.

[7] F. Zhang, Y. F. Gao, Y. X. Wu, and N. Zhang, "Upper-bound solutions for face stability of circular tunnels in undrained clays," Geotechnique, vol. 68, no. 1, pp. 76-85, 2018.

[8] P. Fritz, "Additives for slurry shields in highly permeable ground," Rock Mechanics and Rock Engineering, vol. 40, no. 1, pp. 81-95, 2007.

[9] X. R. Han, W. Zhu, Q. W. Liu, X. C. Zhong, and F. L. Min, "Influence of slurry property on filter cake quality on working face of slurry shield," Rock and Soil Mechanics, vol. 29, pp. 288-292, 2008.

[10] F. L. Min, W. Zhu, X. R. Han, and X. C. Zhong, "The effect of clay content on filter-cake formation in highly permeable gravel," in Geoenvironmental Engineering and Geotechnics, pp. 210-215, 2010.

[11] F. L. Min, W. Zhu, and X. R. Han, "Filter cake formation for slurry shield tunneling in highly permeable sand," Tunnelling and Underground Space Technology, vol. 38, pp. 423-430, 2013.

[12] F. L. Min, W. Zhu, C. Lin, and X. J. Guo, "Opening the excavation chamber of the large-diameter size slurry shield: a case study in Nanjing Yangtze River Tunnel in China," Tunnelling and Underground Space Technology, vol. 46, no. 2, pp. 18-27, 2015.

[13] J.-H. Wu, J. Z. Liu, Y. J. Yu, R. K. Wang, J. H. Zhou, and K. F. Cen, "Improving slurryability, rheology, and stability of slurry fuel from blending petroleum coke with lignite," Petroleum Science, vol. 12, no. 1, pp. 157-169, 2015.

[14] T. Xu and A. Bezuijen, "Bentonite slurry infiltration into sand: filter cake formation under various conditions," Géotechnique, vol. 69, no. 12, pp. 1095-1106, 2019.

[15] C. Liu, J. Sun, P. Yang, and H. B. Wang, "Mesoscopic analysis and model test on formation process and state division of slurry membrane," Chinese Journal of Geotechnical Engineering, vol. 36, no. 3, pp. 435-443, 2014.

[16] C. Liu, Y. Lu, W. H. Lyu, and L. Liu, "Effect of corse-particle materials in slurry on filter cake formation effectiveness in sandy strata," China Journal of Highway and Transport, vol. 31, no. 3, pp. 104-112, 2018.

[17] S. Wang, Y. Huang, and F. Civan, "Experimental and theoretical investigation of the Zaoyuan field heavy oil flow through porous media," Journal of Petroleum Science and Engineering, vol. 50, no. 2, pp. 83-101, 2006.

[18] F. L. Min, J. Du, and N. Zhang, "Experimental study on property change of slurry and filter cake of slurry shield under seawater intrusion," Tunnelling and Underground Space Technology, vol. 88, pp. 290-299, 2019.

[19] N. N. Zhai, W. S. Wang, and B. C. Zheng, "Rheological properties of mud slurry for slurry shield," Chinese Journal of Underground Space and Engineering, vol. 13, no. 4, pp. 5864, 2017.

[20] Z. Zhong, Z. Lei, and M. Linwu, "Mud permeation tests of slurry shield in fault fractured stratum," Journal of Railway Science and Engineering, vol. 17, no. 3, pp. 682-689, 2020.

[21] P. Fritz, S. R. Hermanns, and A. Heinz, "Modified bentonite slurries for slurry shields in highly permeable soils," in 4 th International Symposium Geotechnical Aspects of Underground Construction in Soft Ground, Toulouse, France, 2002.

[22] M. Axelsson and G. Gustafson, "Grouting with high water/solid-ratios -literature and laboratory study. Report no. 2007: 5," Department of Civil and Environmental Engineering, division of GeoEngineering, Chalmers University of Technology, Goeborg, Sweden, 2007.

[23] S. G. A. Bergman, "Tunneltaning. Injektering smedelsintragning i sand och smala spalter. Byggforskningen Rapport R45," Rotobeckman AB, Stockholm, Sweden, 1970.

[24] F. X. Zhang, H. H. Zhu, and D. M. Fu, Shield Tunnel, People's Communication Press, Beijing, 2004.

[25] S. Jancsecz and W. Steiner, "Face support for a large MixShield in heterogeneous ground conditions," in Tunnelling'94, pp. 531-550, Springer, Boston, MA, 1994. 